\title{
HEMODYNAMIC CHANGES FOLLOWING INTRAORAL INJECTION OF LIDOCAINE IN COMBINATION WITH ADRENALINE DURING TOOTH EXTRACTION
}

\author{
Sarah A Haji ${ }^{*}$, Nabeel AJ Ali ${ }^{\#}$ and Sundus AW Neama ${ }^{@}$ \\ ${ }^{*}$ Research fellow, BDS, Department of Oral and Maxillofacial Surgery, College of Dentistry. \\ \#MBChB, PhD (U.K), Professor, Department of Pharmacology, College of Medicine. \\ ${ }^{\circledR} \mathrm{BDS}, \mathrm{MSc}$, Lecturer, Department of Oral and Maxillofacial Surgery, College of Dentistry, University of \\ Basrah, Basrah, IRAQ.
}

\begin{abstract}
Local anesthetic drugs are used in combination with vasoconstrictors, commonly adrenaline which increases their efficacy and duration of action and reduces bleeding at the operative site. However, adrenaline might have adverse hemodynamic effects, especially in patients with cardiovascular diseases. Hypertensive patients represent a risk group in dental practice. One major apprehension of the dentist is the sudden and dramatic increase in blood pressure that could lead to life-threatening complications including sudden death during a dental procedure. The aim of this study is to measure hemodynamic parameters, blood glucose, oxygen saturation and pain score in normotensive and hypertensive patients following intraoral injection of lidocaine with adrenaline and correlate these changes to the level of pain intensity and plasma metanephrine concentration.

This prospective study was conducted at Basrah College of Dentistry from October 2016 to June 2017. One hundred patients were included in the study for teeth extraction under local anesthesia. Sixty normotensives, 30 had stage one hypertension $(\mathrm{BP}=140-159 / 90-99)$ and ten healthy volunteers for metanephrine assay. All patients were injected with two cartridges of $2 \%$ Lidocaine with 1:80,000 adrenaline. Systolic and diastolic blood pressure, heart rate, oxygen saturation, visual analogue scale, blood glucose and plasma metanephrine concentration were measured at different intervals; before anesthetic injection, 5 minutes after injection, during extraction and 10 minutes following the end of tooth extraction.

Administration of local anesthesia with adrenaline in addition to the surgical procedure resulted in a significant increase in systolic blood pressure during tooth extraction $(+8.7 \%$ and $+16.6 \%$ $\mathrm{mmHg}$ for normotensive and hypertensive patients respectively, $\mathrm{p}<0.05$ ), also heart rate similarly affected in both groups (10.6\% and $13.4 \%$ respectively), this effect was significantly higher in the hypertensive group. The blood glucose showed a significant increase $(P=0.00) 30$ minutes after injection as compared to baseline. Generally, the peak changes in parameters were observed during tooth extraction procedure in both groups. Metanephrine peak plasma level occurs at 10 minutes following injection and it was significantly correlated with the systolic and diastolic blood pressure.

In conclusions, the injection of lidocaine with adrenaline in addition to the surgical procedure produces significant increase in blood pressure and heart rate in both normal and hypertensive patients which were larger in the latter group. Similarly, plasma metanephrine concentration was increased during the dental procedure and linked to the increase in the systolic blood pressure.
\end{abstract}

\section{Introduction}

Control of dental pain during dental considered as one of the most important factors for successful treatment ${ }^{1}$. Lidocaine is particularly safe and ideal anesthetics agent since it has a rapid onset, sufficient duration and can be injected with negligible tissue irritation ${ }^{2}$. Adrenaline by constriction of submucosal blood vessels will also reduce bleeding, shorten onset, increase duration of anesthetics' action and decrease risk of systemic toxicity, ${ }^{3,4}$ With all these advantages, adrenaline when absorbed systemically can have undesirable cardiac effects especially in patients with cardiovascular diseases ${ }^{5}$. Hypertension is one of the most common systemic disease 
encountered in patients attended the dental clinic ${ }^{6}$. The use of adrenaline in combination with local anesthetics in hypertensive patients is still a subject of controversy. One important consideration while treating hypertensive patients is the unexpected and dramatic elevation of blood pressure which might lead to serious complication such as hypertensive crisis, angina pectoris, myocardial infarction, and cardiac arrhythias . Adrenaline in combination with local anesthetics agent routinely use in various dental treatment have been reported to elevate arterial pressure in the same manner as other factors such as pain, stress or anxiety ${ }^{8}$. The endogenous discharge of adrenaline and other catecholamines is reported to increase 2040 times during different kinds of stress 9 .

On other hands, Nakamura et al., 2001 found that the inadequate pain control during dental procedures may further increase health risk of patients. Lidocaine without adrenaline (plain anesthesia) may be useful for short procedures after infiltration, however, their effectiveness for nerve block is poor ${ }^{4}$.

Metanephrine constitutes a key metabolite of adrenaline ${ }^{10}$, and it has better stability as compared to adrenaline and it also reflects the sympathetic over activity during stress and dental procedure $^{11-13}$.

The aim of this study is to measure the hemodynamic changes including blood pressure, heart rate and blood glucose, oxygen saturation, pain score in normotensive and hypertensive patients following intraoral injection of lidocaine with adrenaline and correlate these changes to plasma metanephrine concentration.

\section{Methods}

A prospective study was conducted at Basrah College of Dentistry from October 2016 to June 2017. One hundred patients were included in the study who is attending the outpatient clinic for teeth extraction under local anesthesia. Out of these 100 patients, 60 normotensives, 30 had stage one hypertension $(\mathrm{BP}=140$ $159 / 90-99 \mathrm{mmHg}$ ) under treatment and ten healthy volunteers for metanephrine assay. All patients were injected with two cartridges of 2\% Lidocaine with 1:80,000 adrenaline. The study was approved by the local Ethical Committee of the College of Medicine, University of Basrah. Informed consent was obtained from every patient following explanation of the study. The tooth extraction was performed during dental students training under the supervision of a senior dental surgeon.

Patients included in the study were at the age range of 20-70 years. Patients with heart disorders or other systemic diseases or those on $\beta$ blockers, has a history of allergic reaction to the local anesthetic, pregnant women and those with infection at the sites of anesthetic injection were excluded from the study.

The patients were examined in the examination room then referred to the oral surgical unit to rest for 20 minutes. Automatic sphygmomanometer (Philips blood pressure monitoring) was used to measure blood pressure and heart rate simultaneously, measurements were repeated three times, the first reading was neglected, and the mean of the other two readings was calculated. Oxygen saturation was measured by pulse oximeter (Beijing choice electronic, model: MD 300C1) and blood glucose level was measured by a glucometer (Contour, Japan). pain intensity was also evaluated using visual analogue scale by asking the patients to make a mark on a paper strip according to the pain intensity they perceive, where $(0)$ refers to no pain, and (10) represents the worst pain intensity ${ }^{14}$. Local anesthesia was then given using a standard cartridge $(1.8 \mathrm{ml})$ of $2 \%$ lidocaine with $1: 80,000$ adrenaline for inferior alveolar nerve block. A minimum of 5 minutes was allowed to attain local anesthesia (LA) effectiveness. 
After that, the measurements were obtained 5 minutes after injection $\left(\mathrm{T}_{5}\right)$, and 10 minutes after LA injection (during the process of tooth extraction while the dentist used the elevator ) $\left(T_{10}\right)$. In addition to the last measurements, blood glucose level and VAS-P were obtained 30 minutes after LA injection (10 minutes after tooth extraction) $\left(\mathrm{T}_{30}\right)$.

The second part of the current study involves young healthy, disease-free volunteers, not on drug treatment and non-smokers. Each was subjected to periodontal treatment (scaling and root planning) under local anesthesia. On study day blood pressure, heart rate and oxygen saturation were measured; in addition, blood sample was collected from each volunteer for measurement of metanephrine.

A dental student under the supervision of the oral and maxillofacial surgeon injected two cartridges lidocaine with adrenaline in the mandible (inferior alveolar nerve block), and after 5 minutes the operator performed the periodontal treatment. Ten minutes post local anesthetics injection and during the periodontal treatment, a second blood sample drawn from the volunteers and the same parameters were measured. Volunteers were kept in a dental chair for
30 minutes post local anesthetics injection in order to collect a third blood sample.

About $3 \mathrm{ml}$ of blood was collected and transferred from the syringe into labeled EDTA tubes (Ethylenediaminetetraacetic acid) which kept in the cool pack until centrifugation. These samples were centrifuged for 30 minutes, then the plasma layer separated to a plain tube which stored at $-20{ }^{\circ} \mathrm{C}$ until assay. Plasma metanephrine concentration was measured by enzyme link immunoassay analysis (ELISA) within 14 days of blood collection.

Statistical analysis was executed using SPSS version 20. The collected data were presented as a mean \pm standard deviation and analyzed using repeated measure ANOVA. Paired-sample t-test or Wilcoxon signed-rank test were used to analyze the difference in parameters within the groups while the changes from the baseline values in each group were compared by Student's t-test. The homogeneity between the 2 groups was assessed with Pearson's test.

\section{Results}

The demographic data and participant characteristics are shown in Table I.

Table I: Participants characteristics

\begin{tabular}{|l|c|c|}
\hline Patients characteristics & $\begin{array}{l}\text { Normotensive } \\
\text { patients }\end{array}$ & $\begin{array}{l}\text { Hypertensive } \\
\text { patients }\end{array}$ \\
\hline Number & 60 & 30 \\
\hline Male: Female & $30: 30$ & $15: 15$ \\
\hline Age (years; Mean \pm SD) & $38.5 \pm 11.8$ & $52 \pm 8.2$ \\
\hline $\begin{array}{l}\text { Duration of tooth extraction } \\
\text { procedure (minutes) }\end{array}$ & $20.5 \pm 5.5$ & $20.7 \pm 5.4$ \\
\hline
\end{tabular}

The effects of intraoral injection of lidocaine with adrenaline in normotensive patients: In the group of normotensive patients, mean systolic blood pressure (SBP) increased at both 5 and 10 minutes after the injection of lidocaine with adrenaline by $3.4 \%$ and $8.7 \%$ respectively. The increase at 10 minutes was statistically significant $(\mathrm{p}=0.00)$. The blood pressure returned back to baseline measurements at 10 minutes following the end of tooth extraction procedure (Table II).

Diastolic blood pressure and oxygen saturation showed no statistically significant changes. The heart rate was 
significantly increased by $10.6 \%$ at 10 minutes after lidocaine and adrenaline injection (during the extraction) $(\mathrm{p}=0.00)$ when compared to baseline measurements. Similarly, blood glucose showed a statistically significant increase $(\mathrm{P}=0.00)$ from $90.5 \mathrm{mg} / \mathrm{dl}$ at the baseline to $102.2 \mathrm{mg} / \mathrm{dl} 30$ minutes after the injection. There was a statistically significant increase in the level of pain intensity (measured by visual analogue scale-VAS during tooth extraction from $2.9 \pm 2.2$ scores at baseline to $4.9 \pm 2.5$ at 10 minutes after injection as compared to the baseline level $(\mathrm{P}=0.034$. However, the level of pain intensity returned to baseline 30 minutes after the injection of lidocaine with adrenaline.

Table II: Changes in normotensive patients after lidocaine with adrenaline injection during tooth extraction.

\begin{tabular}{|c|c|c|c|c|c|c|}
\hline $\begin{array}{l}\text { Minutes } \\
\text { after } \\
\text { injection }\end{array}$ & $\begin{array}{l}\text { Systolic } \\
\text { pressure } \\
(\mathrm{mmHg})\end{array}$ & $\begin{array}{l}\text { Diastolic } \\
\text { pressure } \\
\text { (mmHg) }\end{array}$ & $\begin{array}{l}\text { Heart } \\
\text { rate } \\
(\text { bpm) }\end{array}$ & $\begin{array}{l}\text { Oxygen } \\
\text { saturation } \\
\%\end{array}$ & $\begin{array}{l}\text { Visual } \\
\text { analogue } \\
\text { scale } \\
\text { (score) }\end{array}$ & $\begin{array}{l}\text { Blood } \\
\text { glucose } \\
\text { (mg/dl) }\end{array}$ \\
\hline 0 & $\begin{array}{l}116.2 \\
\pm 11.8\end{array}$ & $\begin{array}{r}75.5 \\
\pm 7.2 \\
\end{array}$ & $\begin{array}{r}79.8 \\
\pm 14 \\
\end{array}$ & $\begin{array}{c}98 \\
\pm 0.9\end{array}$ & $\begin{array}{c}2.9 \\
\pm 2.2\end{array}$ & $\begin{array}{c}90.5 \\
\pm 13.1\end{array}$ \\
\hline 5 & $\begin{array}{l}119.4 \\
\pm 14.9\end{array}$ & $\begin{array}{l}74.2 \\
\pm 11\end{array}$ & $\begin{array}{c}83.8 \\
\pm 14.3\end{array}$ & $\begin{array}{c}97.9 \\
\pm 1\end{array}$ & - & - \\
\hline 10 & $\begin{array}{c}125.5 \\
\pm 12.6^{*}\end{array}$ & $\begin{array}{r}77.9 \\
\pm 9.8 \\
\end{array}$ & $\begin{array}{r}87.4 \\
\pm 14.7^{*} \\
\end{array}$ & $\begin{array}{c}97.3 \\
\pm 3.04 \\
\end{array}$ & $\begin{array}{c}4.9 \\
\pm 2.5^{*} \\
\end{array}$ & - \\
\hline 30 & $\begin{array}{l}116.8 \\
\pm 12.5\end{array}$ & $\begin{array}{r}74.8 \\
\pm 8.8\end{array}$ & $\begin{array}{l}77.8 \\
\pm 14.7\end{array}$ & $\begin{array}{l}97.9 \\
\pm 0.9\end{array}$ & $\begin{array}{l}1.5 \\
\pm 0.9\end{array}$ & $\begin{array}{c}102.2 \\
\pm 15.8^{*}\end{array}$ \\
\hline
\end{tabular}

Data are expressed as Mean $\pm \mathrm{SD},{ }^{*}$ denotes a statistically significant change, - no reading at this time.

Correlation between pain intensity and other measured parameters at 10 minutes: There was a statistically significant correlation between pain intensity (measured by VAS) and systolic blood pressure during extraction $(\mathrm{p}=0.038)$. While DBP, heart rate and oxygen saturation showed no such significant correlation $(p=0.293,0.225$ and 0.340 respectively).

The effects of lidocaine with adrenaline in hypertensive patients: In hypertensive patients, systolic blood pressure (SBP) was increased from $132.5 \pm 14.6 \mathrm{mmHg}$ at the baseline value to $143.1 \pm 14.9$ and $153.9 \pm 16.6 \mathrm{mmHg}$ at 5 and 10 minutes after lidocaine with adrenaline injections, and this increase was statistically significant at both time intervals $(\mathrm{P}=0.005$ and 0.000 respectively) and returned back to baseline values 30 minutes after the injection (Table III).
The highest heart rate increment was seen 10 minutes post-lidocaine with adrenaline injection with a mean of 91.7 bpm. This increase is statistically significant in comparison to baseline value $81.4 \pm 14 \mathrm{bpm}(\mathrm{p}=0.002)$.

The level of blood glucose was significantly increased from $105.1 \pm 27$ $\mathrm{mg} / \mathrm{dl}$ at the baseline value to116.9 \pm 29.3 $\mathrm{mg} / \mathrm{dl}$ at 30 minutes after injection (10 minutes following tooth extraction) $(\mathrm{P}=0.00)$, However, the glucose level is still within the normal range and none of the patients experienced hypo- or hyperglycemia.

The pain intensity (measured by VAS) during tooth extraction 10 minutes after lidocaine and adrenaline injection were significantly increased to $4.3 \pm 2.3$ scores when compared to the baseline level $2.8 \pm 1.9$ scores $(\mathrm{P}=0.001)$. 
Table III: Changes in hypertensive patients after lidocaine with adrenaline injection during tooth extraction.

\begin{tabular}{|l|l|c|c|l|l|l|}
\hline $\begin{array}{l}\text { Minutes } \\
\text { after } \\
\text { injection }\end{array}$ & $\begin{array}{l}\text { Systolic } \\
\text { pressure } \\
\mathbf{( m m H g )}\end{array}$ & $\begin{array}{l}\text { Diastolic } \\
\text { pressure } \\
\mathbf{( m m H g )}\end{array}$ & $\begin{array}{l}\text { Heart rate } \\
\mathbf{( b p m )}\end{array}$ & $\begin{array}{l}\text { Oxygen } \\
\text { saturation } \\
\mathbf{\%}\end{array}$ & $\begin{array}{l}\text { Visual } \\
\text { analogue } \\
\text { scale } \\
\text { (score) }\end{array}$ & $\begin{array}{l}\text { Blood } \\
\text { glucose } \\
\mathbf{( m g / d l )}\end{array}$ \\
\hline 0 & $132.5 \pm 14.6$ & $81.9 \pm 8.7$ & $81.4 \pm 14$ & $98.1 \pm 0.7$ & $2.8 \pm 1.9$ & $105.1 \pm 27$ \\
\hline 5 & $143.1 \pm 14^{*}$ & $81.5 \pm 7.1$ & $84.5 \pm 15.5$ & $97.8 \pm 1.7$ & - & - \\
\hline 10 & $153.9 \pm 16^{*}$ & $90.7 \pm 15.3$ & $91.7 \pm 18.1^{*}$ & $97.2 \pm 1.6$ & $4.3 \pm 2.3^{*}$ & - \\
\hline 30 & $135.5 \pm 20.4$ & $80 \pm 13$ & $83.4 \pm 15.5$ & $97.7 \pm 1.1$ & $1.3 \pm 0.6$ & $116.9 \pm 29.3^{*}$ \\
\hline
\end{tabular}

Data are expressed as Mean \pm SD, ${ }^{*}$ denotes a statistically significant change, - no reading at this time.

Correlation between pain intensity and the measured parameters at 10 minutes: There was a statistically significant correlation between pain intensity (measured by VAS) and systolic blood pressure and heart rate during extraction ( $\mathrm{p}=0.028$ and 0.004 respectively). While DBP showed no such significant correlation $(\mathrm{p}=0.681)$.

Comparison of different parameters between normotensive and hypertensive groups: 1- Blood pressure: The trends in changes of SBP over time in both groups were demonstrated in figure $(1 a, b)$. These changes follow the same pattern in both groups. The changes in (SBP) between normotensive and hypertensive groups from their baseline value also showed a

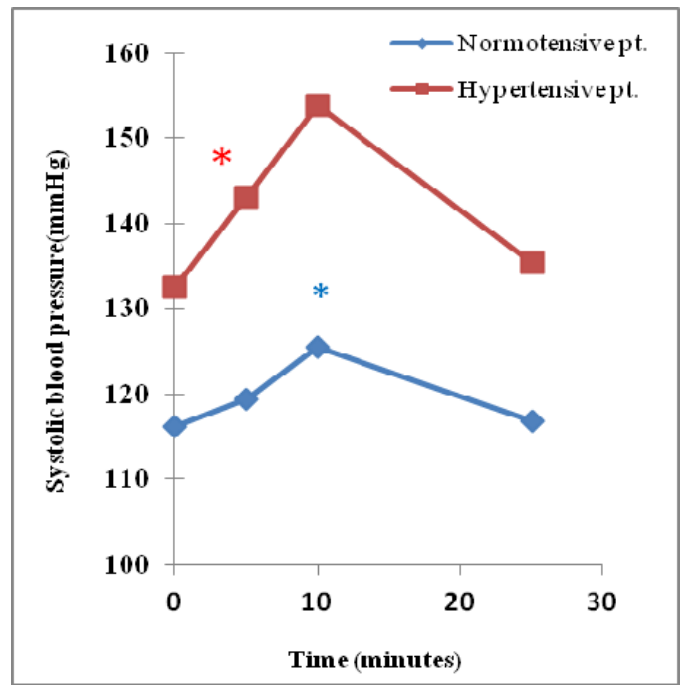

statistically significant difference at 5 and 10 minutes after injections $(\mathrm{P}=0.040$ and 0.002 respectively).

At five minutes after the administration of lidocaine with adrenaline $\left(\mathrm{T}_{5}\right)$, there was a slight and transient decrease in mean DBP in both groups (about -1.3 and -0.4 $\mathrm{mmHg}$ in normal and hypertensive patients respectively). However, during extraction T10, the DBP increased to 77.9 $\mathrm{mm} \mathrm{Hg}$ and $90.7 \mathrm{mmHg}$ in group 1 and 2 respectively and returned to baseline value after tooth extraction $\left(\mathrm{T}_{30}\right)$ without a statistically significant difference. The observed changes of DBP from baseline showed the statistically significant difference $(\mathrm{p}=0.034)$ only during tooth extraction at $\mathrm{T}_{10}$.

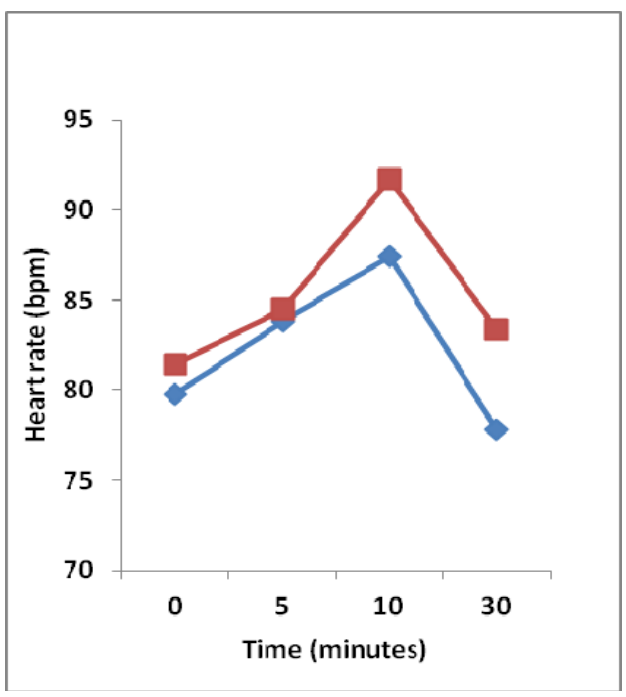

Figure 1: Effect of lidocaine with adrenaline on systolic blood pressure (a) and heart rate (b) of normal and hypertensive patients. * denotes a statistically significant change from baseline. 
Blood glucose: In comparison between groups no significant differences in blood glucose between normotensive and hypertensive groups $(\mathrm{P}=0.952)$.

The effect of lidocaine with adrenaline on plasma metanephrine concentration and hemodynamic changes: Ten young, healthy male volunteers mean age of $22.3 \pm 0.8$ years were subjected to simple periodontal treatment (deep scaling) under lidocaine with adrenaline. A dramatic increase in plasma metanephrine concentrations (PMC) was observed at 10 minutes post lidocaine with adrenaline injection T10 (during treatment) (up to $2451.3 \mathrm{pg} / \mathrm{ml}$ ) and returned back around baseline value after 30 minutes following the injection (after treatment) (mean= 288.2 \pm 79.6 ) (Figure 2).

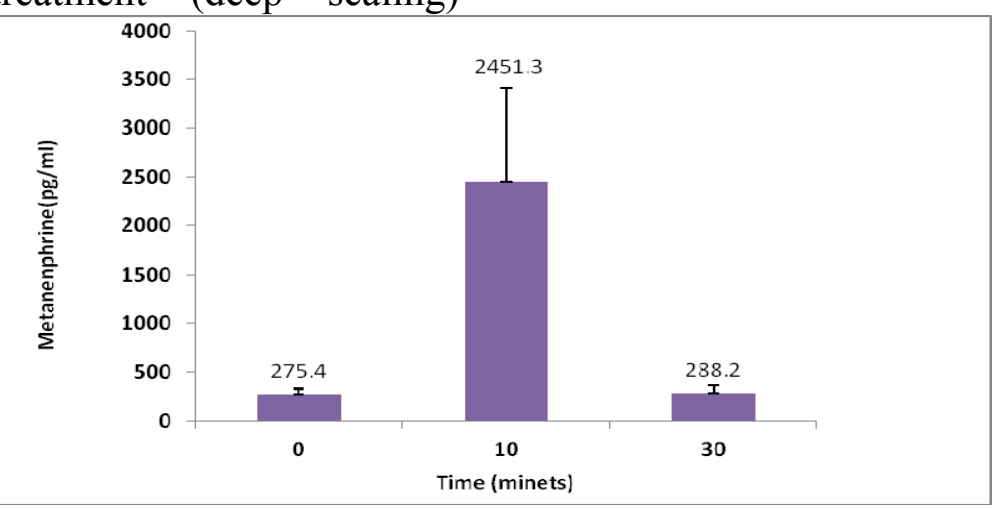

Figure 2: Effect of lidocaine with adrenaline on plasma metanephrine concentration at $\mathbf{0 , 1 0}$ and 30 minutes following lidocaine with adrenaline injection.

At 10 minutes after lidocaine with adrenaline injection $\left(\mathrm{T}_{10}\right)$, There was a statistically significant difference between plasma metanephrine concentration $(\mathrm{P}=0.008)$ as compared to its corresponding baseline value, Similarly, SBP and HR showed a significant increase $(\mathrm{P}=0.002$ and $\mathrm{P}=0.001$ respectively) as compared to their corresponding baseline value. On other hands, DBP showed no statistically significant difference $(\mathrm{p}=0.504)$ Table (IV).

Table IV: The effect of lidocaine with adrenaline on metanephrine concentration and hemodynamic parameters at $\mathbf{T}_{10}$

\begin{tabular}{|c|c|c|c|c|}
\hline $\begin{array}{l}\text { Minutes } \\
\text { after } \\
\text { injection }\end{array}$ & $\begin{array}{l}\text { Metanephrine } \\
\text { (pg/ml) }\end{array}$ & $\begin{array}{l}\text { Systolic blood } \\
\text { pressure (mmHg) }\end{array}$ & $\begin{array}{l}\text { Diastolic blood } \\
\text { pressure (mmHg) }\end{array}$ & $\begin{array}{l}\text { Heart } \\
\text { rate } \\
\text { (bpm) }\end{array}$ \\
\hline T0 & $275.4 \pm 56.7$ & $109.8 \pm 7.5$ & $67.1 \pm 5.2$ & $75.6 \pm 7.7$ \\
\hline $\mathrm{T} 10$ & $2451.3 \pm 962.7$ & $122.5 \pm 12.9$ & $68.2 \pm 7.7$ & $87.8 \pm 9.9$ \\
\hline P value & $0.008^{*}$ & $0.002 *$ & 0.504 & $0.001^{*}$ \\
\hline
\end{tabular}

Data are expressed as Mean $\pm \mathrm{SD},{ }^{*}$ denotes a statistically significant change.

The changes in systolic blood pressure at T10 minutes (during treatment) and 30minutes (after treatment) following lidocaine with adrenaline injection from their corresponding baseline value were strongly correlated with the changes in the plasma metanephrine concentration at the same periods. $(\mathrm{P}=0.020 \quad-\mathrm{r}=0.717$ and $\mathrm{P}=0.000 \quad-\mathrm{r}=0.896 \quad$ respectively). The changes in diastolic blood pressure at 10 minutes following the injection of lidocaine with adrenaline (during treatment) from their corresponding baseline value (T10-T0)was strongly correlated with the changes in the plasma metanephrine concentration at the same periods. $(\mathrm{P}=0.004-\mathrm{r}=0.811) \quad($ Figure 3$)$. 

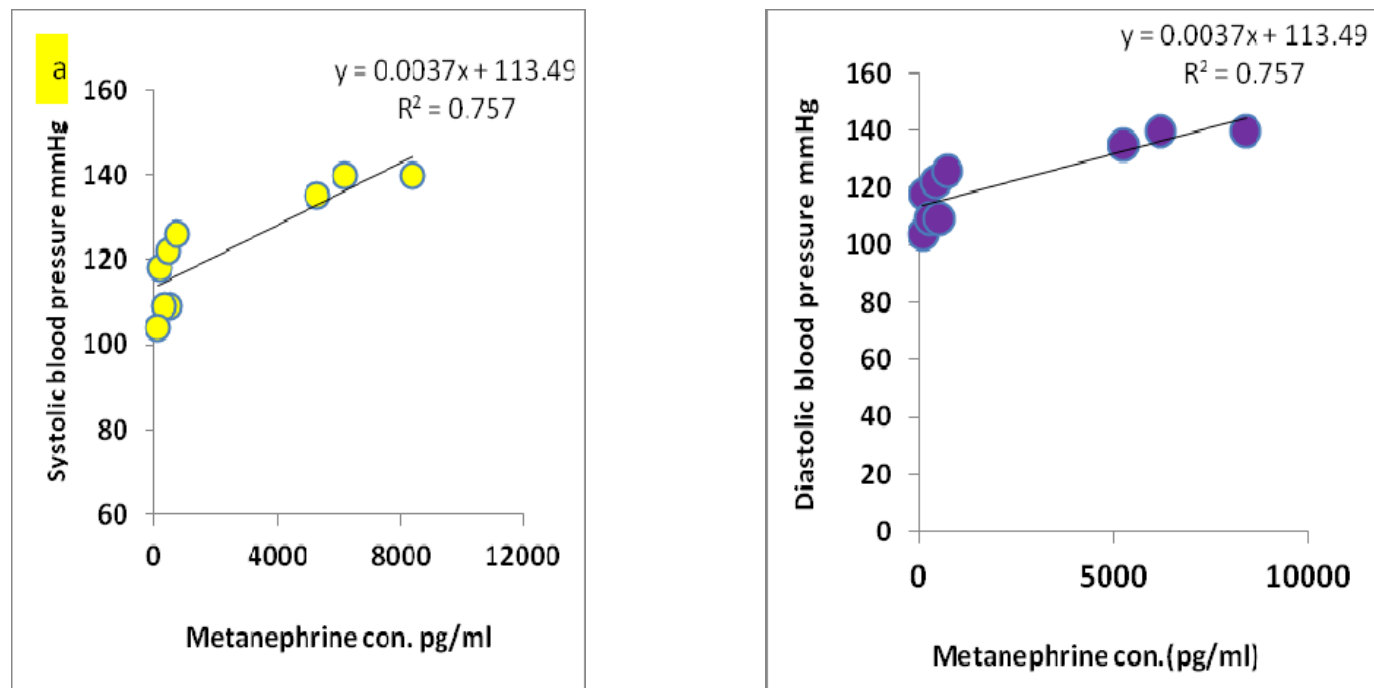

Figure 3: Correlation between plasma metanephrine concentration and systolic (a) and diastolic (b) blood pressure at 10 minutes following lidocaine with adrenaline injection.

While there was no statically significant correlation between changes of plasma Metanephrine concentration and heart rate from their corresponding baseline value at 10 and 30 minutes post local anesthetics injection $(\mathrm{P}=0.329-\mathrm{r}=0.345$ and $\mathrm{P}=0.121-\mathrm{r}=0.523$ respectively).

\section{Discussion}

The current study demonstrated in normotensive and hypertensive patients, a significant increase in systolic blood pressure, heart rate and visual analogue scale of pain occur at 10 minutes after intraoral injection of lidocaine with adrenaline during extraction. Diastolic blood pressure and oxygen saturation showed no significant changes as compared to baseline values in both groups. Levels of blood glucose showed a significant elevation from the baseline values at the end of the tooth extraction. There was a significant correlation between the level of pain intensity (measured by VAS) and systolic blood pressure and heart rate during extraction.

Lidocaine in combination with adrenaline during a surgical procedure in the current study was found to increase systolic blood pressure; Such increase was significantly larger in hypertensive patients than the normotensive patients. This is possibly due to the difference in tissue response to adrenaline in hypertensive patients ${ }^{15}$. Abraham Inpijn et al, $1988^{16}$ in their study observed that hypertensive patients undergoing tooth extraction experience a greater increase in blood pressure as compared to the normotensive group after intraoral injection of $2 \%$ lidocaine with 1:100,000 adrenaline.

Our study is in agreement with Niwa et al., $2001^{17}$ who evaluated twenty-seven patients with cardiovascular disease who received an intraoral injection of lidocaine plus adrenaline, they found significant cardiovascular changes 10 minutes post injection and they speculated that these changes were limited and within the normal ranges. It was also observed that heart rate and systolic blood pressure elevated from the baseline by $5.1 \%$ and $4.1 \%$, correspondingly, while diastolic blood pressure decreased by approximately 10 $\%$. This effect is explained by the stress during the dental surgical procedure and the effect of external adrenaline . $^{8}$

The maximum hemodynamic effects in our study were detected at 10 minutes following the injection. This time coincided with the use of dental elevator during extraction procedure, the effect of the pressure of the elevator is not abolished by the local anesthesia, and the 
patient may remain anxious by a sense of pressure regardless of entire anesthesia of the pain fibers ${ }^{4}$, such increase may be further attributed to other factors such as psychological and physical stress since these changes occurred in both groups during extraction ${ }^{18}$.

Psychological and physiological stress enhance the release of the endogens catecholamines which in turn give rise to change in the hemodynamic parameters, as its well-known that the released endogenous adrenaline is much greater than that used in dental practice ${ }^{19}$. The possibility of intravascular injection of local anesthesia cannot be excluded as the aspiration technique during the injection process is not used.

In the current study, the measured parameters returned back to baseline reading 10 minutes after the completion of tooth extraction as the stress and fear induced by surgical procedure, were terminated $^{16}$. Furthermore, In the current study, we found that diastolic blood pressure increased at 10 minutes post local anaesthetics injection in a similar way to systolic blood pressure but to less extent, this finding is in agreement with previous studies ${ }^{5,20,21}$.

There was a significant increase of heart rate during extraction in both groups as compared to their corresponding baseline values; However, the differences between the normotensive and hypertensive were not significant. Such increase may be attributed to the fact that heart rate and cardiac contraction are increased due to activation of $B 1$ receptors on the sinoatrial node $^{22}$.

The finding of the current study was in agreement with other studies that report no significant changes in oxygen saturation in both normotensive and hypertensive groups ${ }^{23,24}$.

The effect of local anesthetic administration with adrenalin upon the level of blood glucose has been studied and there was much controversy about this effect. It was observed that there was no significant change in level of blood glucose 10 minutes following the procedure in comparison to the baseline value $^{25}$, however, another study detected changes in plasma catecholamines and blood glucose in normotensive patients during tooth extraction and they found that the injection of $2 \%$ lidocaine with 1:80,000 adrenaline and tooth extraction resulted in statically significant increases in plasma adrenaline concentration and serum glucose level during tooth extraction and they demonstrated that there was a close correlation between the adrenaline concentration and serum glucose ${ }^{26}$.

In the current study, blood glucose level exhibited statistically significant increase at the end of the tooth extraction as compared to baseline value. This increase in adrenaline (whether exogenous or endogenous) through activation of the $\beta$ receptor can enhance the glycogenolysis in the liver and increase glucagon secretion on another hand, adrenaline can inhibit insulin secretion and cause transient hyperglycemia ${ }^{27}$.

The increase in glucose level may be small and momentary and can be tolerated by patients with normal insulin sensitivity, however, in diabetic patients, it may be of importance ${ }^{26}$.

Part 2: We measured the plasma metanephrine (adrenaline metabolite) due to its better stability as compared to adrenaline and it reflects the sympathetic overactivity during stress and dental procedure $^{11-13}$.

There was a dramatic increase in plasma metanephrine concentrations with the peak value occur during the dental procedures. Such increase was associated with elevated systolic blood pressure and heart rate. The elevation can be attributed to both the administered adrenaline in addition to the stress or fear associated with dental treatment which resulted in increased circulating levels of adrenaline metabolite $^{28}$. Numerous studies tried to measure plasma catecholamine levels 
following intraoral injections of local anesthetic with adrenaline and tried to correlate it to the hemodynamic reactions. Some found that following injection of one cartridge of $2 \%$ lidocaine with $1: 100,000$ adrenaline there was a two to three-fold increase in plasma catecholamine levels as compared to their corresponding baseline levels with nonsignificant hemodynamic effects ${ }^{29-31}$. It's worthwhile to notice that these studied were using (only) one cartridge of lidocaine containing adrenaline with different dilution ratio as in our study, in addition to the different study population. Other studies observed that intraoral injections of local anesthetics with adrenaline increase the plasma adrenaline levels and associated with a cardiovascular alteration ${ }^{32-33}$. The consideration of premedication with anxiolytic drugs or beta blockers prior to the dental procedure should be considered in patients at cardiovascular risks.

In Conclusion, there was a significant increase (elevation) in both systolic blood pressure and heart rate occurs during dental procedure in normal and hypertensive patients with more increase in the latter group, also there was a significant increase in blood glucose level following the dental procedure but it does not exceed the normal range. Similarly, metanephrine concentration was increased during the dental procedure and it was correlated to the increase in the systolic and diastolic blood pressure. Generally, the hemodynamic changes and the increase of blood glucose could be attributed to the excessive catecholamines of exogenous and/or endogenous origin.

\section{References}

1. Moore PA, Boynes SG, Hersh EV, DeRossi SS, Sollecito TP, Goodson JM, et al. The anesthetic efficacy of 4 percent articaine 1: 200,000 epinephrine: two controlled clinical trials. The Journal of the American Dental Association. 2006;137(11):1572-81.

2. de Morais HHA, de Santana Santos T, da Costa Araújo FA, de Freitas Xavier RL, Vajgel A, de Holanda Vasconcellos RJ. Hemodynamic changes comparing 2\% lidocaine and 4\% articaine with epinephrine 1: 100,000 in lower third molar surgery. Journal of Craniofacial Surgery. 2012;23(4):1204-11.

3. Haas DA. An update on local anesthetics in dentistry. J Can Dent Assoc. 2002;68(9):546-51.

4. Becker DE, Reed KL. Local Anesthetics: Review of Pharmacological Considerations. Anesthesia progress. 2012;59(2):90-102.

5. Meral G, Tasar F, Sayin F, Saysel M, Kir S, Karabulut E. Effects of lidocaine with and without epinephrine on plasma epinephrine and lidocaine concentrations and hemodynamic values during third molar surgery. Oral Surg Oral Med Oral Pathol Oral Radiol Endod. 2005;100(2):031.

6. Matsumura K, Miura K, Takata Y, Kurokawa H, Kajiyama M, Abe I, et al. Changes in blood pressure and heart rate variability during dental surgery. American journal of hypertension. 1998;11(11):1376-80.

7. Gungormus M BM. The evaluation of the changes in blood pressure and pulse rate of hypertensive patients during tooth extraction. Acta Med Austriaca. 2003;30:127-7.

8. Silvestre F, Verdú M, Sanchis J, Grau D, Peñarrocha M. Effects of vasoconstrictors in dentistry upon systolic and diastolic arterial pressure. Medicina oral: organo oficial de la Sociedad Espanola de Medicina Oral y de la Academia Iberoamericana de Patologia y Medicina Bucal. 2000;6(1):57-63.

9. Balakrishnan R, Ebenezer V. Contraindications of vasoconstrictors in dentistry. Biomed Pharmacol J. 2013;6(2):409-14.

10. Goldstein DS, Eisenhofer G, Kopin IJ. Sources and Significance of Plasma Levels of Catechols and Their Metabolites in Humans. Journal of Pharmacology and Experimental Therapeutics. 2003;305(3):800-11.

11. Lenders JW, Pacak K, Walther MM, Linehan WM, Mannelli M, Friberg P, et al. Biochemical diagnosis of pheochromocytoma: which test is best? Jama. 2002;287(11):1427-34.

12. Lee GR, Johnston PC, Atkinson A, McKillop D, Auld P, Hunter SJ. A comparison of plasma-free metanephrines with plasma catecholamines in the investigation of suspected pheochromocytoma. Journal of hypertension. 2011;29(12):2422-8.

13. Hickman PE, Leong M, Chang J, Wilson SR, McWhinney B. Plasma free metanephrines are superior to urine and plasma catecholamines and urine catecholamine metabolites for the investigation of phaeochromocytoma. Pathology. 2009;41(2):173-7. 
14. Dexter F, Chestnut DH. Analysis of statistical tests to compare visual analog scale measurements among groups. Anesthesiology. 1995;82(4):896-902.

15. Bible D, MEGAN J, DOMINIC N. A systematic review of cardiovascular effects of ephinefrine on cardiac compromised dental patient. Community dentistry Evidence based in learning module University of Toronto. 2008.

16. Abraham-Inpijn L, Borgmeijer-Hoelen A, Gortzak RT. Changes in blood pressure, heart rate, and electrocardiogram during dental treatment with use of local anesthesia. The Journal of the American Dental Association. 1988;116(4):531-6.

17. Niwa H, Sugimura M, Satoh Y, Tanimoto A. Cardiovascular response to epinephrine-containing local anesthesia in patients with cardiovascular disease. Oral Surg Oral Med Oral Pathol Oral Radiol Endod. 2001;92(6):610-6.

18. Alemany-Martínez A, Valmaseda-Castellón E, Berini-Aytés L, Gay-Escoda C. Hemodynamic changes during the surgical removal of lower third molars. Journal of oral and maxillofacial surgery. 2008;66(3):453-61.

19. Meyer FU. Haemodynamic changes under emotional stress following a minor surgical procedure under local anaesthesia. Int J Oral Maxillofac Surg. 1987;16(6):688-94.

20. Ketabi M, Shamami MS, Alaie M, Shamami MS. Influence of local anesthetics with or without epinephrine 1/80000 on blood pressure and heart rate: A randomized double-blind experimental clinical trial. Dental Research Journal. 2012;9(4):437-40.

21. Faraco FN, Kawakami PY, Mestnik MJ, Ferrari DS, Shibli JA. Effect of anesthetics containing lidocaine and epinephrine on cardiovascular changes during dental implant surgery. J Oral Implantol. 2007;33(2):84-8.

22. Madrid C, Courtois B, Vironneau M. Recommendations to use vasoconstrictors in dentistry and oral surgery. Med Bucc Chir Bucc. 2003;9(2):1-30.

23. Carrera Grañó I, Mestre R, Berini Aytés L, Gay Escoda C. Alterations in monitored vital constants induced by various local anesthetics in combination with different vasoconstrictors in the surgical removal of lower third molars. Bulletin du GIRSO, 2000, vol 42, num 1, p 1-10. 2000.

24. Mestre RA, Carrera IG, Berini LA, Gay CE. Pulsioxymetry monitorization during lower third molar extraction. A comparative study of three local anesthetics with epinephrine 1: 100,000. Medicina oral: organo oficial de la Sociedad Espanola de Medicina Oral y de la Academia Iberoamericana de Patologia y Medicina Bucal. 2001;6(3):195-204.

25. Tily FE, Ajman ST. Glycemic effect of administration of epinephrine-containing local anaesthesia in patients undergoing dental extraction, a comparison between healthy and diabetic patients. International dental journal. 2007;57(2):77-83.

26. Nakamura Y, Matsumura K, Miura K, Kurokawa H, Abe I, Takata Y. Cardiovascular and sympathetic responses to dental surgery with local anesthesia. Hypertension Research. 2001;24(3):209-14.

27. Kalra P, Rana A, Peravali RK, Gupta D, Jain G. Comparative evaluation of local anaesthesia with adrenaline and without adrenaline on blood glucose concentration in patients undergoing tooth extractions. Journal of maxillofacial and oral surgery. 2011;10(3):230-5.

28. Kudva YC, Sawka AM, Young Jr WF. The laboratory diagnosis of adrenal pheochromocytoma: the Mayo Clinic experience. The Journal of Clinical Endocrinology \& Metabolism. 2003;88(10):4533-9.

29. Chernow B, Balestrieri F, Ferguson CD, Terezhalmy GT, Fletcher JR, Lake CR. Local dental anesthesia with epinephrine: minimal effects on the sympathetic nervous system or on hemodynamic variables. Archives of internal medicine. 1983;143(11):2141-3.

30. Tolas AG, Pflug AE, Halter JB. Arterial plasma epinephrine concentrations and hemodynamic responses after dental injection of local anesthetic with epinephrine. The Journal of the American Dental Association. 1982;104(1):41-3.

31. Taylor S, Achola K, Smith G, Donegan J. Plasma Catecholamine Concentrations: The Effects of Infiltration with Local Analgesics and Vasoconstrictors During Nasal Operations. Survey of Anesthesiology. 1985;29(2):104.

32. Dionne RA, Goldstein DS, Wirdzek PR. Effects of diazepam premedication and epinephrine-containing local anesthetic on cardiovascular and plasma catecholamine responses to oral surgery. Anesthesia \& Analgesia. 1984;63(7):640-6.

33. Goldstein DS, Dlonne R, Sweet J, Gracely R, Brewer Jr BH, Gregg R, et al. Circulatory, plasma catecholamine, cortisol, lipid, and psychological responses to a real-life stress (third molar extractions): effects of diazepam sedation and of inclusion of epinephrine with the local anesthetic. Psychosomatic Medicine. 1982;44(3):259-72. 